\title{
Short-term International Migration Trends in England and Wales from 2004 to 2009
}

Simon Whitworth, Konstantinos Loukas and Ian McGregor

Office for National Statistics

\begin{abstract}
Short-term migration estimates for England and Wales are the latest addition to the Office for National Statistics (ONS) migration statistics. This article discusses definitions of shortterm migration and the methodology that is used to produce the estimates. Some of the estimates and the changes in the estimates over time are then discussed. The article includes previously unpublished short-term migration statistics and therefore helps to give a more complete picture of the size and characteristics of short-term international migration for England and Wales than has previously been possible. ONS have identified a clear user requirement for short-term migration estimates at local authority (LA) level. Consequently, attention is also paid to the progress that has been made and future work that is planned to distribute England and Wales short-term migration estimates to LA level.
\end{abstract}




\section{Introduction}

The short-term international migration statistics series was developed in response to the recommendations made in the 2006 Report on the Inter-departmental Task Force on Migration Statistics ${ }^{1}$ that highlighted the importance of having accurate and sufficiently detailed short-term migration statistics. Short-term migration refers to international migration made for short durations, specifically moves made for between one month and less than a year. This distinguishes shortterm migration from long-term international migration statistics which refer to international moves made for a year or more.

The aim of this article is to give an update on ONS's response to the 2006 Report on the Interdepartmental Task Force on Migration Statistics and identify the progress made in the development of short-term international migration statistics. Initial work on the feasibility of shortterm migration statistics was presented in the Population Trends article 'The feasibility of making short-term migration estimates' ${ }^{2}$, and this article discusses progress made since then. Furthermore, this article presents some key short-term migration statistics that were previously released in a statistical bulletin published by ONS in February 2011. These statistics are complemented with a more detailed analysis and previously unpublished statistics in order to give a more complete picture of the size and characteristics of short-term international migration in to and out of England and Wales. Finally, the article discusses the progress that has been made and future work that is planned to distribute England and Wales short-term migration estimates to LA level.

England and Wales estimates of short-term migration are produced for a wide range of users including central and local government agencies. Data is collected on various migrant characteristics, such as reason for visit, nationality and duration of stay, so that the resulting statistics can best meet user requirements. Data on the flows and the duration of stay of short-term migrants are essential to support policy making and monitoring as well as facilitation of academic research.

Further uses can arise from potential geographic breakdowns of flow and stock estimates of shortterm migrants. Central government departments and LAs (especially those with a high proportion of short-term migrant workers) can use these statistics to assess community needs and inform demands and specific needs on public services such as schools and hospitals. Furthermore, LA short-term migration estimates can be used for reconciliation between ONS population estimates, which do not include short-term migrants, and various administrative sources which include both short and long-term migrants.

\section{Background}

In its 2006 report, the Inter-departmental Task Force on Migration Statistics highlighted the need to have timely and accurate estimates of short-term migration for different reasons for migration.

Before the development of short-term migration statistics, population and migration statistics for England and Wales were based solely on the United Nations (UN) definition of a long-term migrant. According to the UN, a long-term international migrant is a person who moves to a country other than that of his or her usual residence for a period of at least a year (12 months), so that the 
country of destination effectively becomes his or her new country of usual residence ${ }^{3}$. Statistics on migrants who change their usual residence for periods of less than a year were not routinely published in England and Wales because of the limited data available to separately identify this group of migrants.

In October 2007 ONS published a first set of experimental estimates of short-term migration for England and Wales. In the following years and as part of the further development of this product, ONS has undertaken a detailed review of the methodology and processing of the short-term migration estimates. In January 2011 the statistics were assessed by the UK Statistics Authority against the National Statistics Code of Practice and were granted National Statistic status ${ }^{4}$.

\section{Definition of a short-term migrant}

The starting point for estimating short-term migration is the identification of a suitable definition. Central to this definition is the need to distinguish between a visitor to a country and a migrant. While a stay of one day might be assumed to be a visit and a stay of 12 months indicative of migration, lengths of stay between these points may be more difficult to categorise. In addition to this, it is also unclear which reasons for visit should be regarded as migration. A short-term migration definition should therefore include criteria that take into account both length of stay and reason for visit.

The UN define a short-term migrant as being 'a person who moves to a country other than that of his or her usual residence for a period of at least three months but less than a year (12 months) except in cases where the movement to that country is for purposes of recreation, holiday, visits to friends and relatives, business, medical treatment or religious pilgrimage, ${ }^{3}$.

ONS publishes estimates of overseas visitors to the UK and visits abroad by UK residents. A visitor is a person who travels into or out of the UK for a period of less than 12 months for holiday, visiting friends or family, business, study, health, religious, recreation and other purposes. The ONS definition of a visitor however, excludes long-term migrants or people travelling overseas to take up prearranged employment ${ }^{5}$.

\section{Figure 1 Overlap between UN short-term migrant and ONS visitor definitions}

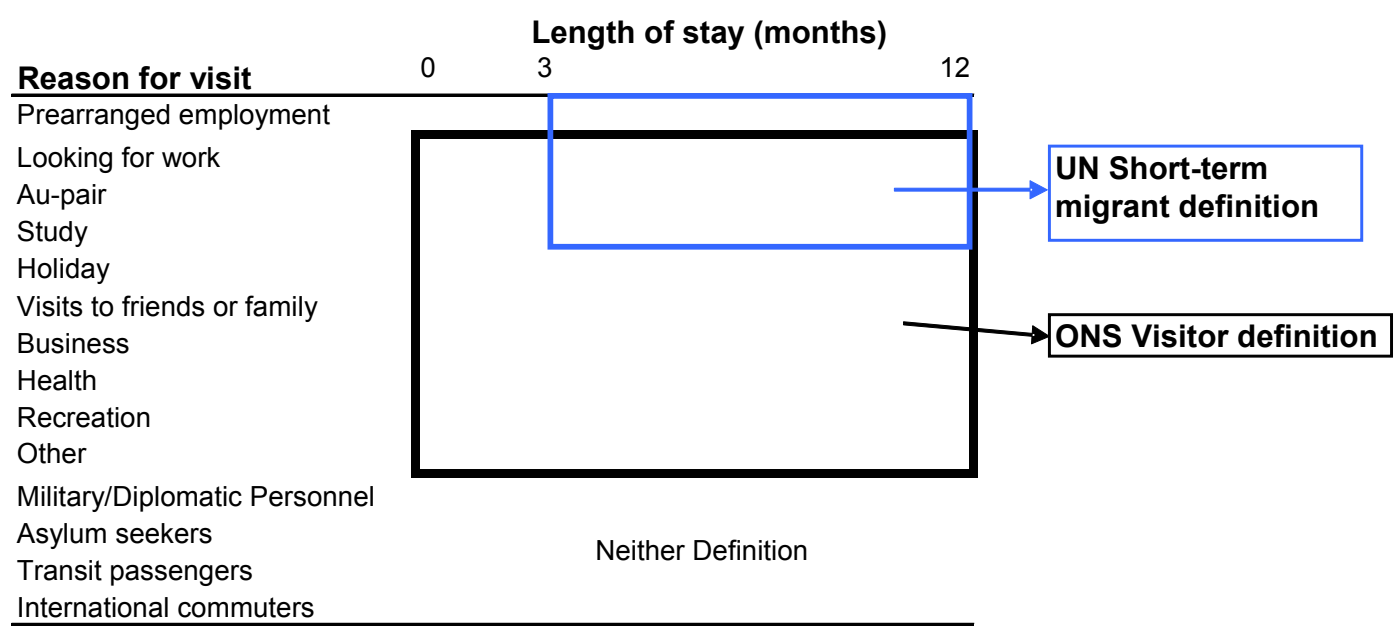


There is an overlap between the UN short-term migrant and the ONS visitor definitions. Figure 1 shows this overlap in more detail.

As previously mentioned, both reason for visit and length of stay need to be considered when constructing a definition of short-term migration. The interaction between these two elements leads to a number of possible definitions. ONS undertook research to explore possible extensions to the UN short-term migrant definition to see how the needs of users could be best met. Users of migration statistics were asked by ONS to feed back comments on several possible definitions of a short-term migrant ${ }^{6}$. The UN definition was used as a starting point and then extensions to this definition were proposed, broadened by reason for visit and/or length of stay.

All respondents suggested the UN definition is important and that it was required as a minimum. In addition, there were requests to extend this definition in the following ways:

a) Migration for reasons other than employment or study for 3 to 12 months: local government organisations suggested that this category is important to get a more complete picture of LA level population statistics

b) Migration for employment or study reasons for 1 to 3 months: this category includes seasonal agricultural workers and therefore rural LAs expressed an interest in getting statistics on this category. London Boroughs with a high proportion of short-term migrant workers also expressed interest

c) Migration for reasons other than employment or study for 1 to 3 months: this was not seen as being as important as the other categories but there was some interest in the suggested reduction of the minimum length of stay criterion to 1 month

Consequently ONS decided to publish short-term migration statistics which met several definitions, thereby meeting the needs of users better. Short-term migration estimates would be published for both 1-12 month and 3-12 month periods and for three purposes of migration: employment, study, and other reasons.

\section{Annual England and Wales Short-term Migration Estimates}

After gaining feedback from a range of users, since the production of the first set of short-term migration estimates in 2007, a new method for calculating standard errors around short-term migration stock estimates was introduced. The timeliness of the estimates was improved by eight months by making use of provisional IPS data. In 2010 a case was put to the UK Statistics Authority to consider the estimates for National Statistic status. The UK Statistics Authority's overall role is to promote and safeguard the production and publication of official statistics that serve the public good. It is also required to promote and safeguard the quality and comprehensiveness of official statistics, and to promote good practice in relation to official statistics.

The experimental annual England and Wales short-term migration estimates were assessed by the UK Statistics Authority against the strict requirements of the Code of Practice for Official Statistics and were granted National Statistic status in February 2011. Consequently, the latest England and Wales short-term migration estimates were released as a statistical bulletin with National Statistic status on 24 February $2011^{7}$. 


\section{Methodology}

\section{International Passenger Survey}

Estimates of short-term international migration flows are produced directly from the International Passenger Survey (IPS) ${ }^{8}$. The IPS is a sample survey of passengers arriving at, and departing from, UK air and sea ports and the Channel Tunnel. Travellers on these routes make up around 90 per cent of all travellers entering and leaving the UK. Its primary use is to capture data on international tourism and to compile the travel account of the Balance of Payments. The survey is also used to provide data on the numbers and characteristics of migrants. The main IPS sample consists of more than 250,000 interviews annually. In 2009 the IPS had an overall response rate of 83 per cent and about 1.7 per cent of those sampled were short-term migrants by at least one of the definitions. This amounted to 4,168 interviews. The IPS sample is stratified to ensure that it is representative of mode of travel, route and time of day. Interviews are conducted throughout the year. The information collected by the survey is weighted to produce national estimates of migration.

\section{Sampling short-term migrants at the end of trip}

Any international short-term visit consists of two moves - a move from the country of origin to the destination country, followed by a move out of the destination country. Short-term migrants can therefore be sampled on either the first or second of these moves. Sampling of passengers at the start of their trip is an 'intended flow' whereas sampling of passengers at the end of their trip is a 'completed flow'. For example, an overseas short-term migrant who comes to the country for three months is considered an inflow and he/she could potentially be sampled when they arrive or alternatively when they depart after the end of the 3-month period. In a similar way, a UK resident who migrates to an overseas destination for three months is considered to be an outflow and he/she can be sampled either when they depart or when they arrive back in the country at the end of their 3-month visit.

The primary advantage of intended flow data is that it is more timely than completed flow data. There are, however, difficulties associated with intended flows, that relate to uncertainty on various migrant characteristics important for short-term migration estimates. For example, individuals may be unsure how long they intend to stay or change their initial plans. Intended destination is another area of uncertainty as migrants can subsequently move to another area. Finally, individuals may arrive in the country for one purpose but stay for other reasons.

Due to these difficulties, ONS uses completed flows data to produce the short-term migration estimates ${ }^{9}$. According to the short-term migrant definition a short-term migrant can stay up to a year in the place of destination. This means that IPS completed flow data for the short-term migration estimates are available 12 months after the end of the reference period. ONS publishes short-term migration estimates for mid-year periods (1 July to 30 June) and uses eight quarters of IPS data to produce a mid-year estimate. This means that each mid-year estimate for short-term migration contains relevant records from three years' results from the IPS. For example the 2007/08 estimate contains records from:

- 2007 IPS (migrants who arrived after July 2007 and who were surveyed on departure before January 2008 after staying in the UK for at least 1 month) 
- 2008 IPS (migrants who arrived after July 2007 and who were surveyed between January 2008 and December 2008 after staying in the UK for between 1 and 12 months)

- 2009 IPS (migrants who arrived before July 2008 and stayed between 6 and 12 months and were surveyed on departure any time up to the end of June 2009).

To improve timeliness, ONS uses provisional IPS data for the last two quarters. Differences between estimates based on final data only and estimates based on a combination of final and provisional data are minimal.

\section{Estimates of short-term migration stocks}

Given that long-term migrants must stay for longer than 12 months to qualify as 'long-term', any long-term migrant who enters England and Wales will still be present at the end of the year and can therefore be added into the usual resident population (stock) estimate. By contrast, short-term migrants stay for less than a year and therefore are not counted as part of the resident population.

However, to meet user needs a methodology has been developed to produce short-term migration stock estimates. This methodology measures the total amount of time, as recorded in the IPS, spent in England and Wales by all short-term migrants between 1 July and 30 June the next year. In effect the method generates a 'long-term migrant equivalent' (LTME).

Figure 2 demonstrates how short-term migrants contribute to the LTME. The long-term migration estimate is calculated for the period between points (i) and (ii). Any days spent by short-term migrants in this period contribute to the LTME. Individual B contributes days spent between (i) and the end of their stay (y). Days spent before point (i) do not contribute to the estimate. Likewise any days spent after point (ii) also do not contribute to the estimate. The total days spent in the 12month period by all short-term migrants are aggregated and then divided by 365 (or 366 in a leap year) to produce an estimate expressed in person years, equivalent to long-term migration stays.

\section{Figure 2 Short-term migration moves in or out of England and Wales between two fixed points in time (i) and (ii)}

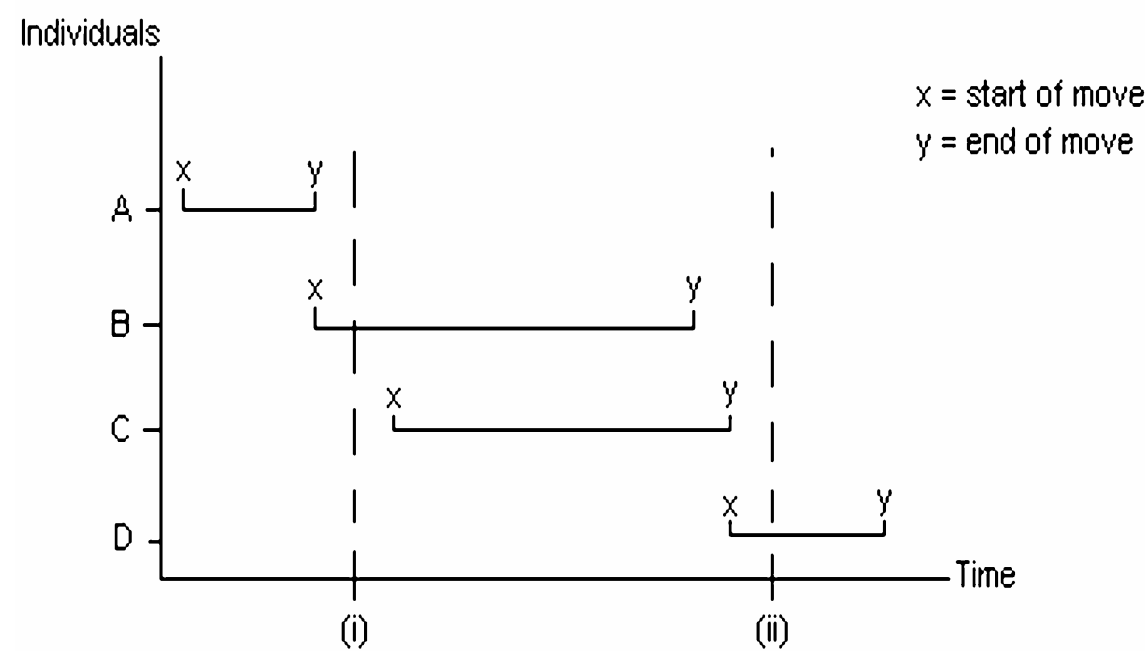


A short-term migration stock estimate can be interpreted as being the average number of shortterm migrants in or out of England and Wales at any given point in the mid-year. For example, assuming a sample of three short-term migrants enter the country with lengths of stay between three and 12 months. Short-term migrant number one stays for 5 months (152 days). Migrant number two stays for 4 months (122 days) and migrant number three stays for 3 months (91 days). These migrants could have entered at the same time or at different points in the mid-year. In this example, the sample represents three inflows but only one stock of migrants. The stock figure results from summing all the days that these migrants spent in the mid-year period, divided by the number of days in a year $(152+122+91) / 365$.

\section{Short-term international migration flows for England and Wales from 2004 to 2009}

The IPS collects information on the migrants' primary purpose of visit. According to their stated reason for visit, migrants can be grouped into three broad categories: workers, students and others. The workers category includes short-term migrants who migrate for employment related purposes. They may have a definitive job to go to or be looking for a job. Students are those migrants who state study as their primary reason for migration. Some of them may take some form of employment during their studies; however their primary purpose for visit is to study. The last group, others, includes all other reasons for visit except for employment or study. This group consists predominantly of people who migrate for holidays, or to visit friends or family, or accompany other people.

This section presents statistics on short-term international migration into and out of England and Wales for work, study and other purposes. Each group of migrants is discussed separately and the focus is on the size of the flows, the nationality of migrants, and their length of stay. All the estimates presented below refer to moves into or out of England and Wales made for between one and 12 months.

\section{Flows of short-term international migration}

Figure 3 shows short-term international migration flows to and from England and Wales for the years mid-2004 to mid-2009. In the year to mid-2009 an estimated 97,000 short-term migrants came to England and Wales for employment-related purposes. This is a 40 per cent reduction from the year to mid-2008. Short-term migration for employment related purposes increased by 84 per cent from mid-2004 to mid-2006, which was the year with the largest worker inflow. Since its peak in the year to mid-2006, the workers inflow has been declining. The percentage decline from mid2006 to mid-2009 (the most recent estimate) was 53 per cent.

Inflows of short-term migrant workers with A8 nationality show the same trend as the overall worker inflow. The 'Accession 8' countries (Czech Republic, Estonia, Hungary, Latvia, Lithuania, Poland, Slovakia and Slovenia) joined the European Union in May 2004. According to IPS data, from mid-2004 to mid-2006 the inflow of A8 short-term migrant workers increased from 28,000 to 131,000 . The year to mid-2006 was the year with the largest inflow of A8 short-term migrant workers. From mid-2006 to mid-2009, short-term inflow of A8 nationals for work-related purposes showed a downward trend and decreased by 67 per cent. 


\section{Figure 3 Short-term International Migration to England and Wales for work and study, mid-2004 to mid-2009}

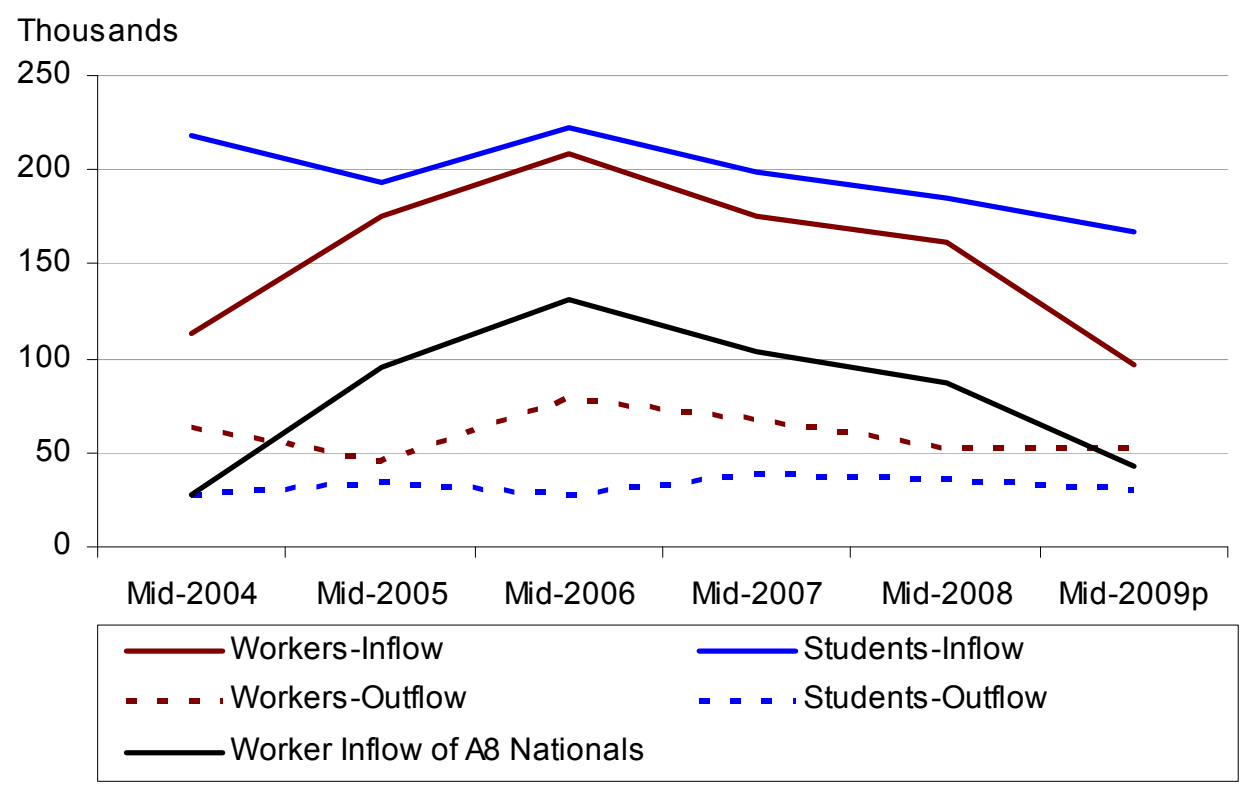

Source: International Passenger Survey, Office for National Statistics Note: $p$ - provisional

IPS data show that employment-related short-term migration makes up a significant proportion of the migrant workforce in England and Wales. In the year to mid-2009, inflow of short-term migrant workers was estimated to be 97,000 , while long-term migration to England and Wales for workrelated purposes was estimated to be 168,000 for the calendar year $2009^{10}$.

Inflow of short-term migrants for study purposes has remained consistently higher than the inflow of workers for all years. The inflow of short-term migrant students was estimated to be 167,000 in the year to mid-2009, a 10 per cent drop from the previous year and the third consecutive fall in the time series. The stock of short-term migrant students in England and Wales for the year to mid2009 was estimated at 46,000 .

Short-term outflows for work or study purposes remained stable over the time series with the worker outflow being consistently higher than the student outflow. Short-term outflows of England and Wales residents are lower than inflows for both work and study related reasons. Therefore, for work and study reasons, fewer short-term migrants are leaving England and Wales to visit overseas countries, than short-term migrants from overseas visiting England and Wales.

Figure 4 shows short-term migration for England and Wales for reasons other than work or study. This category primarily consists of people who move into or out of England or Wales for holiday purposes or visiting family or friends. In the year to mid-2009, the number of people who visited England and Wales for purposes other than employment or study was estimated to be 864,000 . The outflow of residents to overseas destinations for 'other' reasons was estimated to be 2.5 million, which was almost three times the size of the inflow for the same year. 


\section{Figure 4 Short-term International Migration to England and Wales for other reasons, mid-2004 to mid-2009}

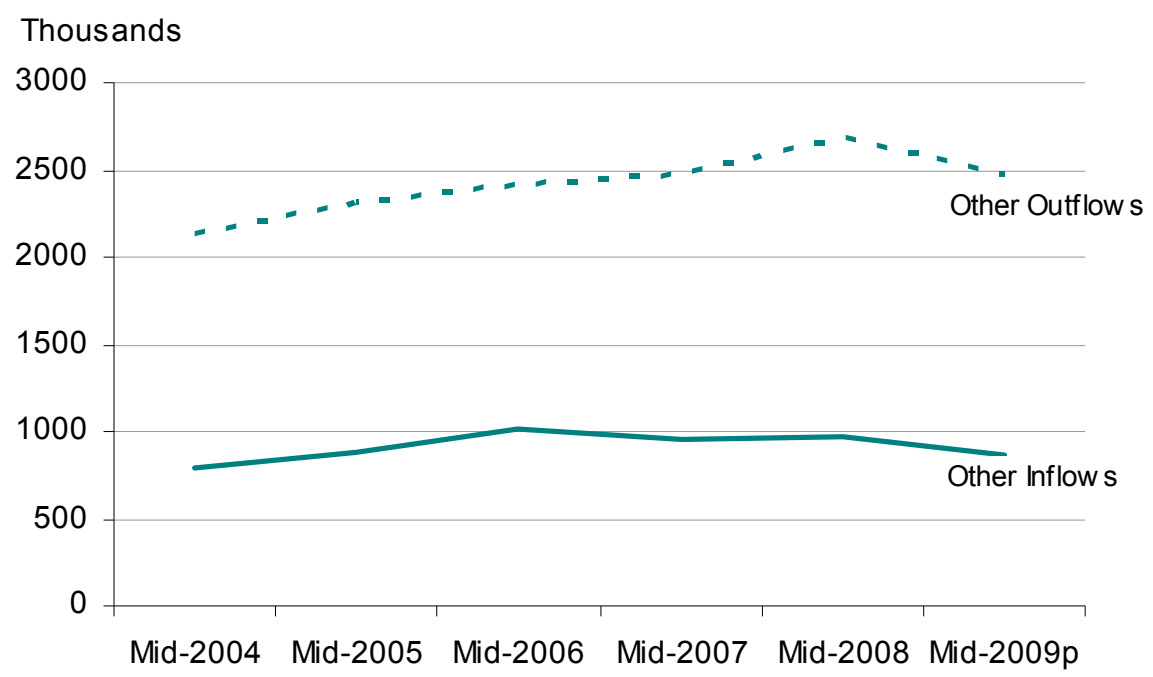

Source: International Passenger Survey, Office for National Statistics Note: $p$ provisional

For the year to mid-2009 inflows for other reasons accounted for 77 per cent of total short-term inflow. Inflows for study accounted for 15 per cent and inflows for employment accounted for 9 per cent. For the same year, outflows for other reasons for visit accounted for 97 per cent of the total outflow, while outflows for employment accounted for 2 per cent and outflows for study accounted for only 1 per cent.

\section{Short-term international migration by length of stay}

Figure 5 shows short-term migration inflows by length of stay as a percentage of total short-term inflow. The data is cumulative for mid-2004 to mid-2009 and inflows of each group are presented separately. In general, short-term migration inflow for any reason for visit decreases as duration of stay increases. For short-term migrant workers the trend is slightly different due to the fact that most short-term migrant workers stayed for between two and three months instead of one to two. Migrants who visited England and Wales for 'other' reasons show a steeper decline in the second month of their stay compared with students and workers. This is because most people in this group are holidaymakers or they visit friends and family and therefore a shorter duration of stay is expected.

Short-term migrant workers who stayed for more than three months accounted for 47 per cent of the total worker inflow. The respective percentage was lower for the other two groups. Specifically, 37 per cent of the short-term migrant student inflow stayed for more than three months and only 17 per cent of the 'other' short-term migrant inflow stayed for more than three months. 
Figure 5 Short-term international migration inflows to England and Wales by length of stay as a percentage of total inflow: shown for workers, students and 'others'

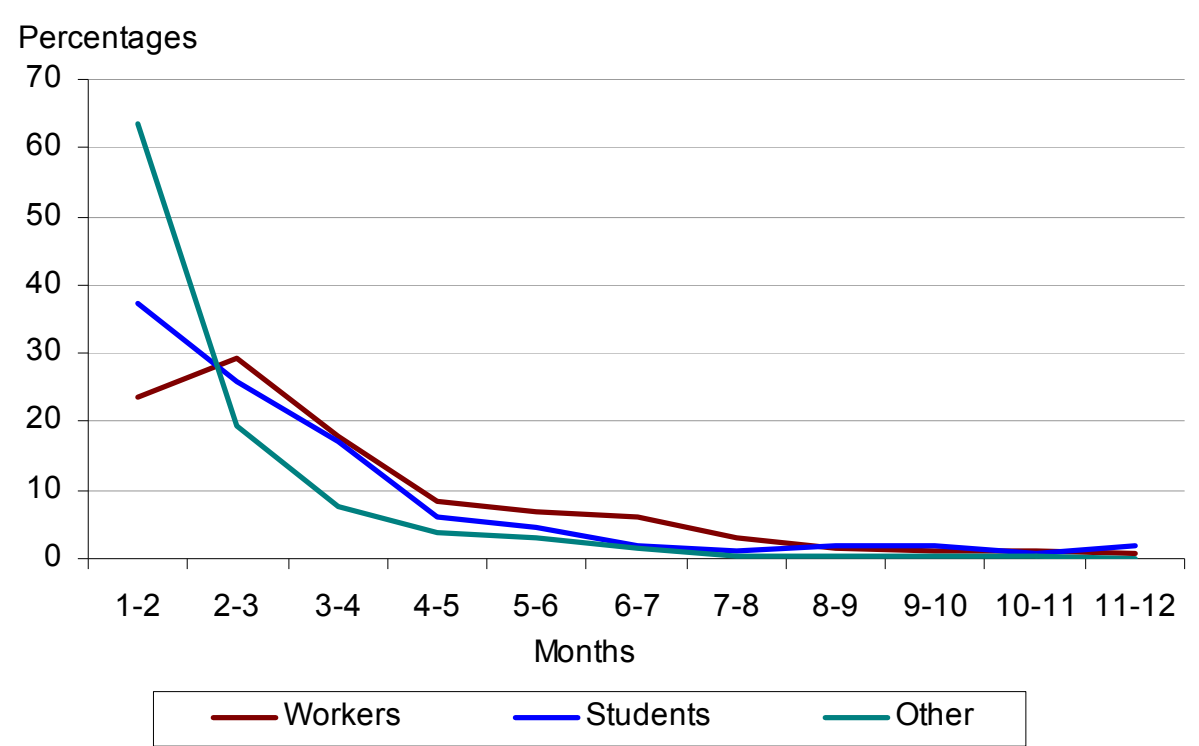

Source: International Passenger Survey, Office for National Statistics Note: Data is cumulative from mid-2004 to mid-2009

Figure 6 Short-term international migration outflows from England and Wales by length of stay as a percentage of total outflow: shown for workers, students and 'others'

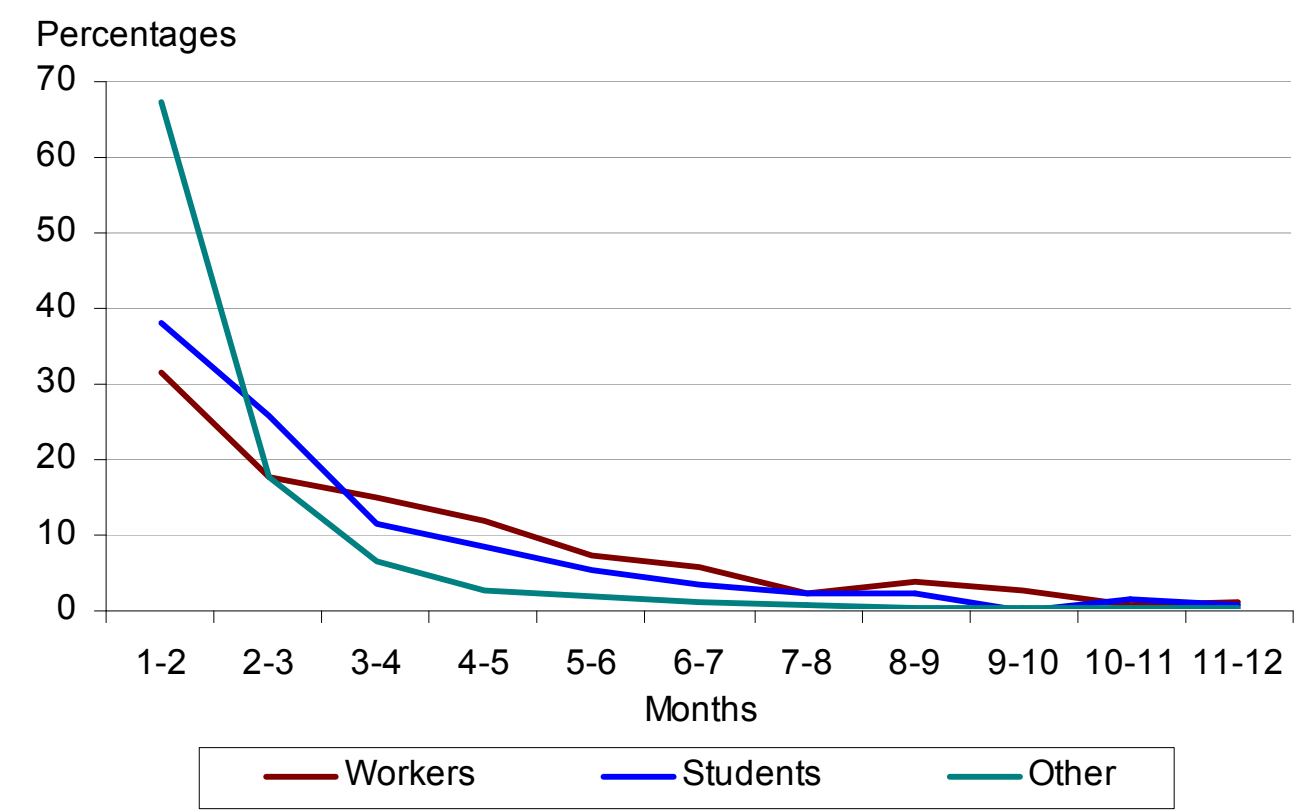

Source: International Passenger Survey, Office for National Statistics Note: Data is cumulative from mid-2004 to mid-2009 
Figure 6 shows short-term migration outflows by length of stay as a percentage of total outflows. Short-term migration outflows follow a downward trend as duration of stay increases. Short-term migrant workers who stayed for more than three months accounted for 51 per cent of the total worker outflow. The respective percentage was lower for the other two groups. Specifically, 36 per cent of the student outflow stayed for more than three months and only 15 per cent of the 'other' short-term migrant outflow stayed for more than three months.

\section{Short-term international migration by nationality}

Figure 7 shows a breakdown of the short-term inflows into England and Wales of migrant workers by nationality group. The group EU-A12 includes the A8 countries plus Malta, Cyprus, Bulgaria and Romania. The graph shows the impact that the $2004 \mathrm{EU}$ enlargement had on employment related short-term migration to England and Wales. While in the year to mid-2004 the A12 countries accounted for 30 per cent of the total short-term worker inflow; in the year to mid-2007 this proportion increased to 65 per cent. By mid-2009 this had dropped to 51 per cent of the total short-term worker inflow.

\section{Figure 7 Short-term International Migration workers inflow to England and Wales by nationality group, mid-2004 to mid- 2009}

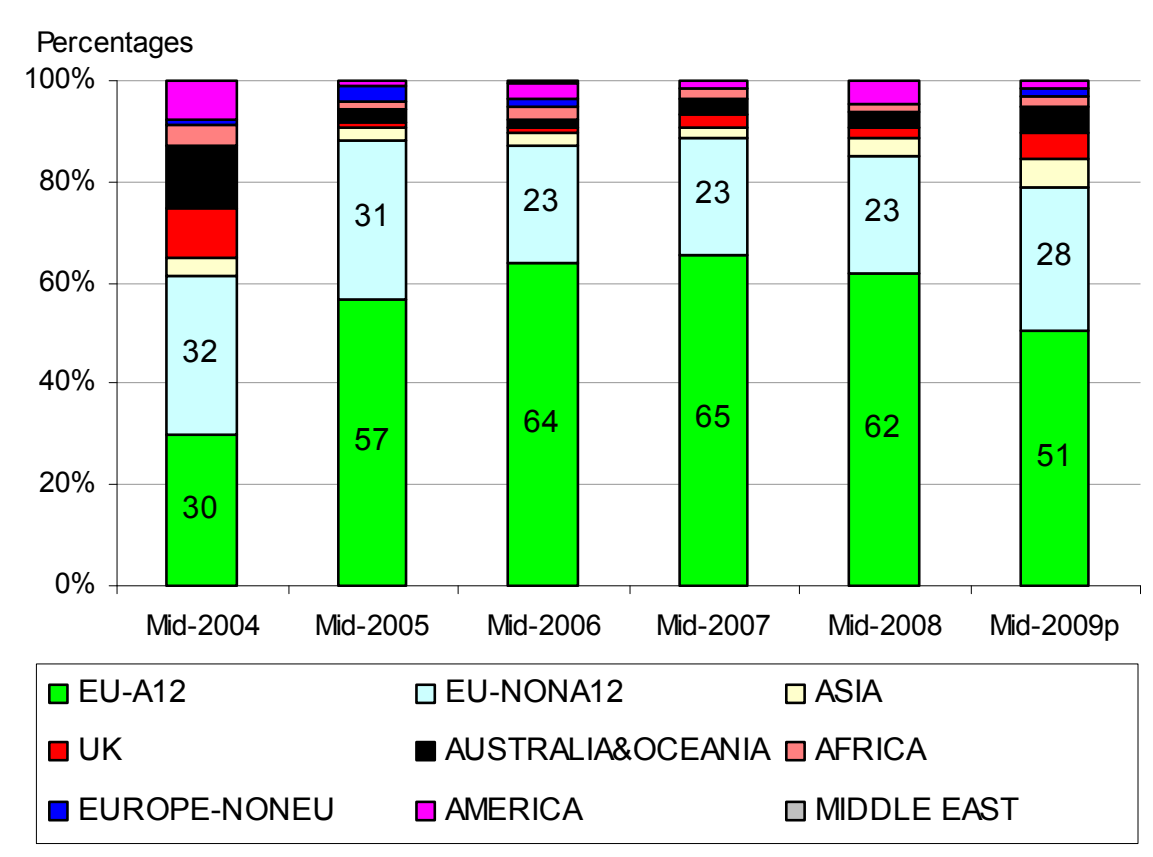

Source: International Passenger Survey, Office for National Statistics Note: p provisional

Figure 8 shows student inflows into England and Wales by nationality. The nationality breakdown of the student inflow is different from that of the workers (Figure 5). Student inflows from the European Union (excluding the A12 countries) accounted for the largest proportion of total students' inflow in each year. Inflows of students from America and Asia also accounted for a significant proportion in each year. 


\section{Figure 8 Short-term International Migration students inflow to England and Wales by nationality group, mid-2004 to mid- 2009}

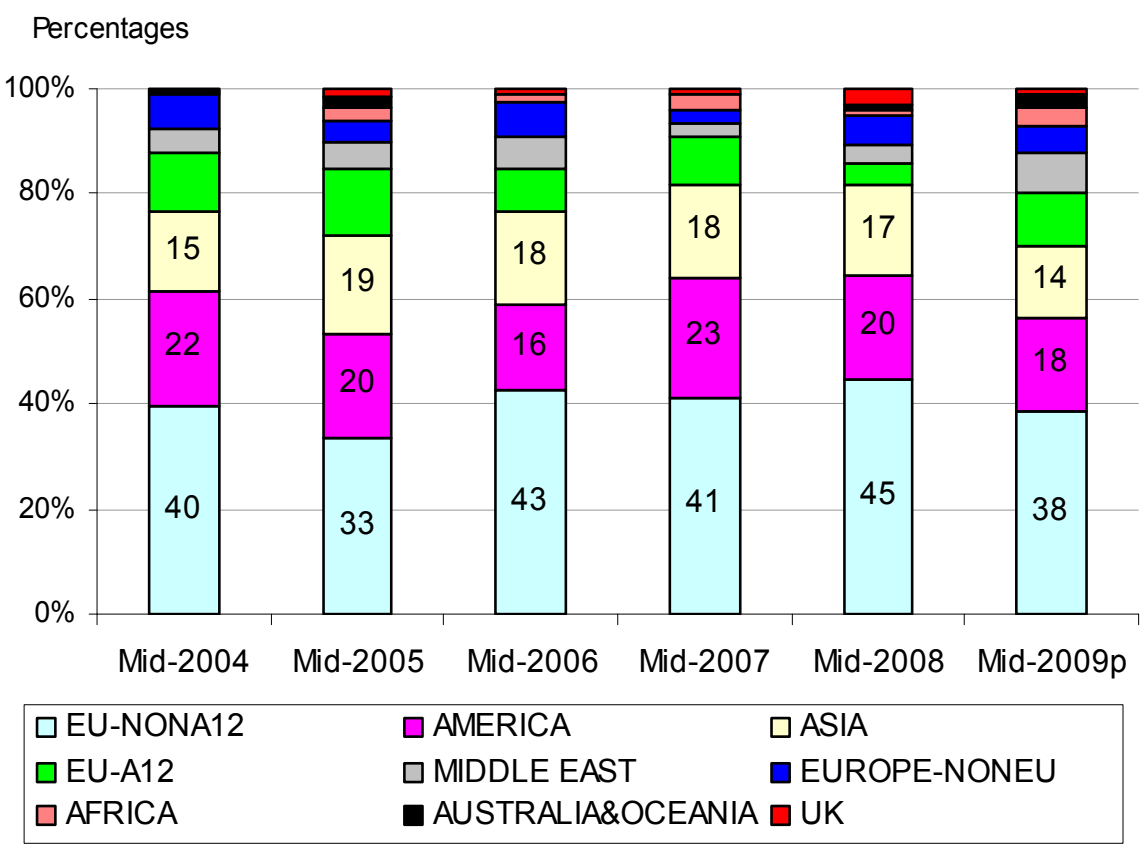

Source: International Passenger Survey, Office for National Statistics Note: p provisional

\section{Figure 9 Short-term International Migration inflow for other reasons to England and Wales by nationality group, mid-2004 to mid-2009}

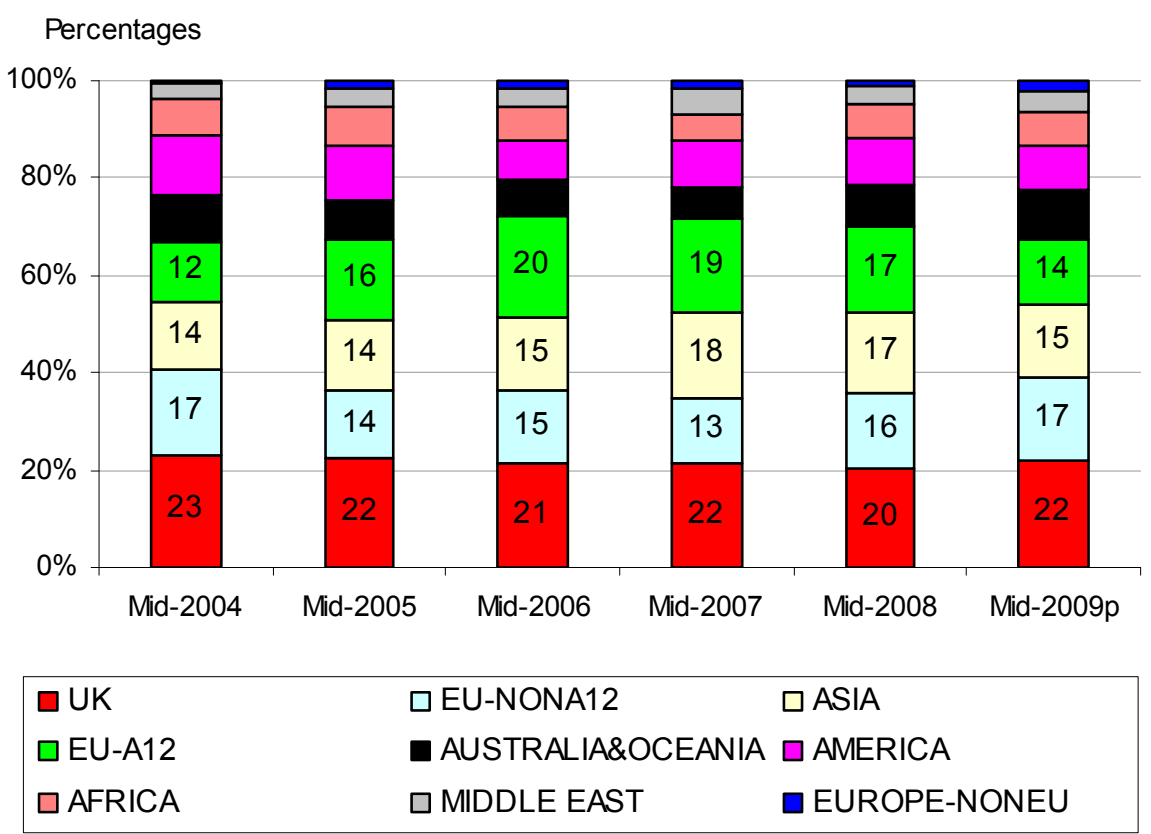

Source: International Passenger Survey, Office for National Statistics Note: $p$ provisional 
Figure 9 shows the nationality breakdown of the third group of migrants - those who came to England and Wales for reasons other than employment or study. The breakdown is different from that of workers or students. Looking at the A12 nationals separately, the data shows that their 'other' inflow as percentage of total 'other' inflow from all countries decreased from 20 per cent in mid-2006 to 14 per cent in mid-2009. This reduction can be linked to the fact that inflows of $A 12$ nationals for work-related purposes have also been decreasing since mid-2006. As many shortterm migrants come to England and Wales to visit family and friends or as dependants, the migration trends of 'others' and 'workers' show similar patterns.

Figure 10 provides a more detailed breakdown of short-term migration inflow. It shows the top five countries of previous residence for short-term migrants in England and Wales for all reasons for visit. It should be noted that a person's previous country cannot always be compared with their nationality. IPS data shows that while the inflows from some countries of previous residence such as Poland, are predominantly Polish nationals, inflows from other countries of previous residence, such as France or Spain, consist of a large proportion of UK nationals.

\section{Figure 10 Most common countries of previous residence (based on mid-2009 rankings) for short-term migrants in England and Wales, mid-2004 to mid-2009}

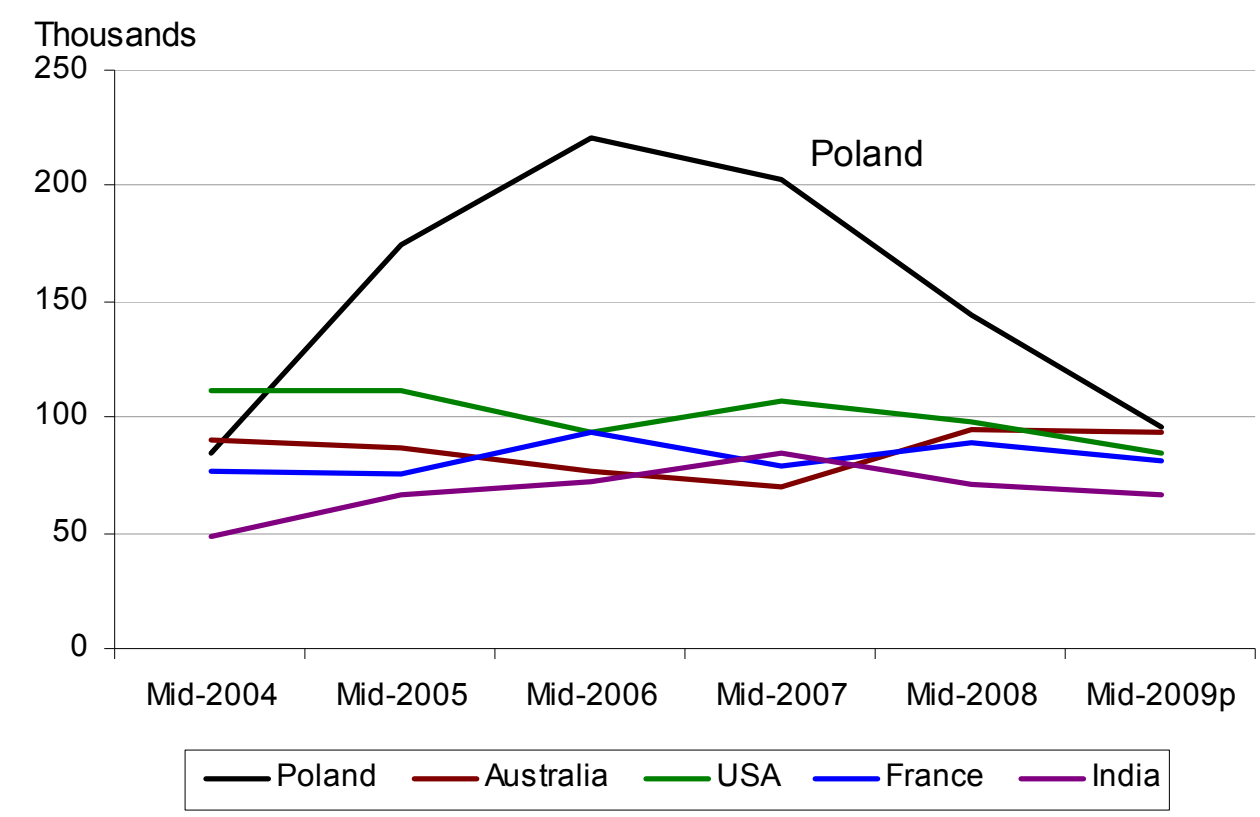

Source: International Passenger Survey, Office for National Statistics Note: p provisional

Short-term migration to England and Wales for all reasons for visits from Poland shows a very similar trend to work-related migration to England and Wales (see Figure 3). In the year to mid2004 , Poland was the third most popular country of previous residence with an estimated 85,000 short-term migrants visiting England and Wales. From mid-2004 to mid-2006 short-term migration from Poland increased by 160 per cent. From the year up to mid-2006 to the year up to mid-2009 the number of short-term migrants from Poland decreased by 57 per cent. An estimated 96,000 short-term migrants from Poland were present in England and Wales in the year to mid-2009. 


\section{Figure 11 Short-term International Migration outflows from England and Wales for all reasons: by nationality, mid-2004 to mid- 2009}

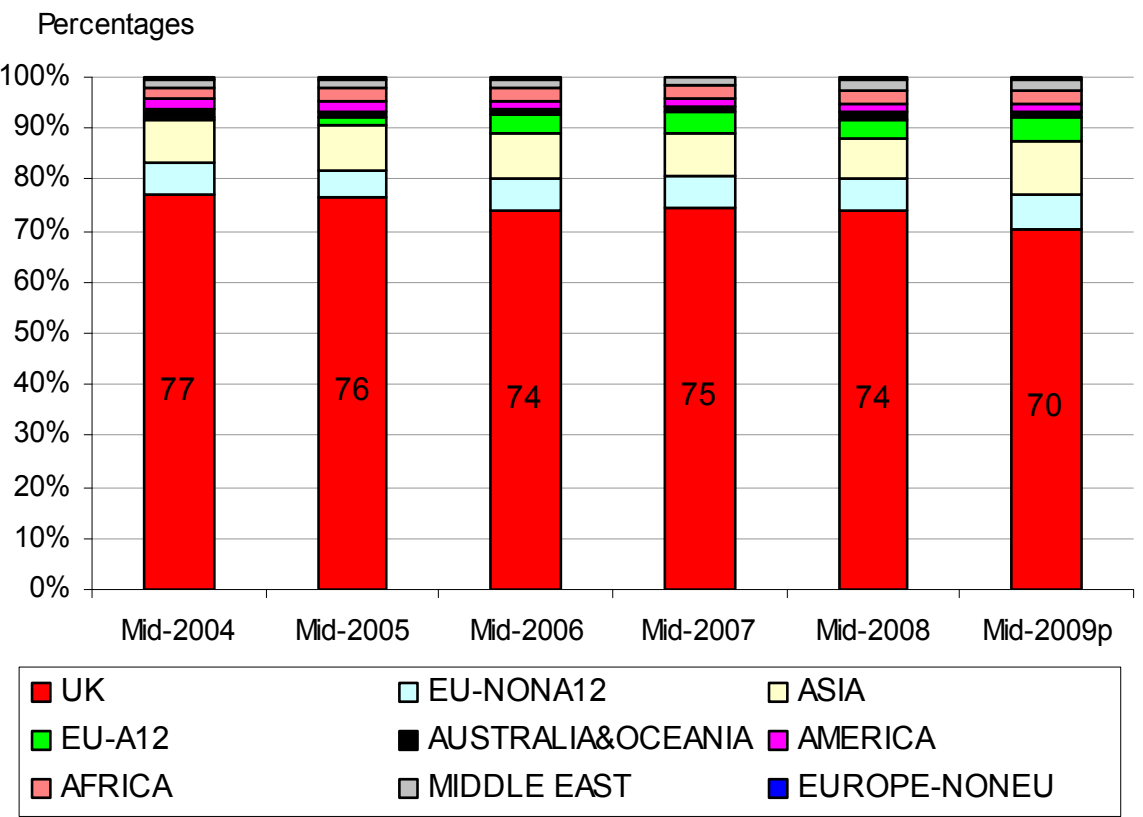

Source: International Passenger Survey, Office for National Statistics Note: p provisional

\section{Figure 12 Most common countries visited for all reasons (based on mid-2009 rankings) shown for mid-2004 to mid-2009}

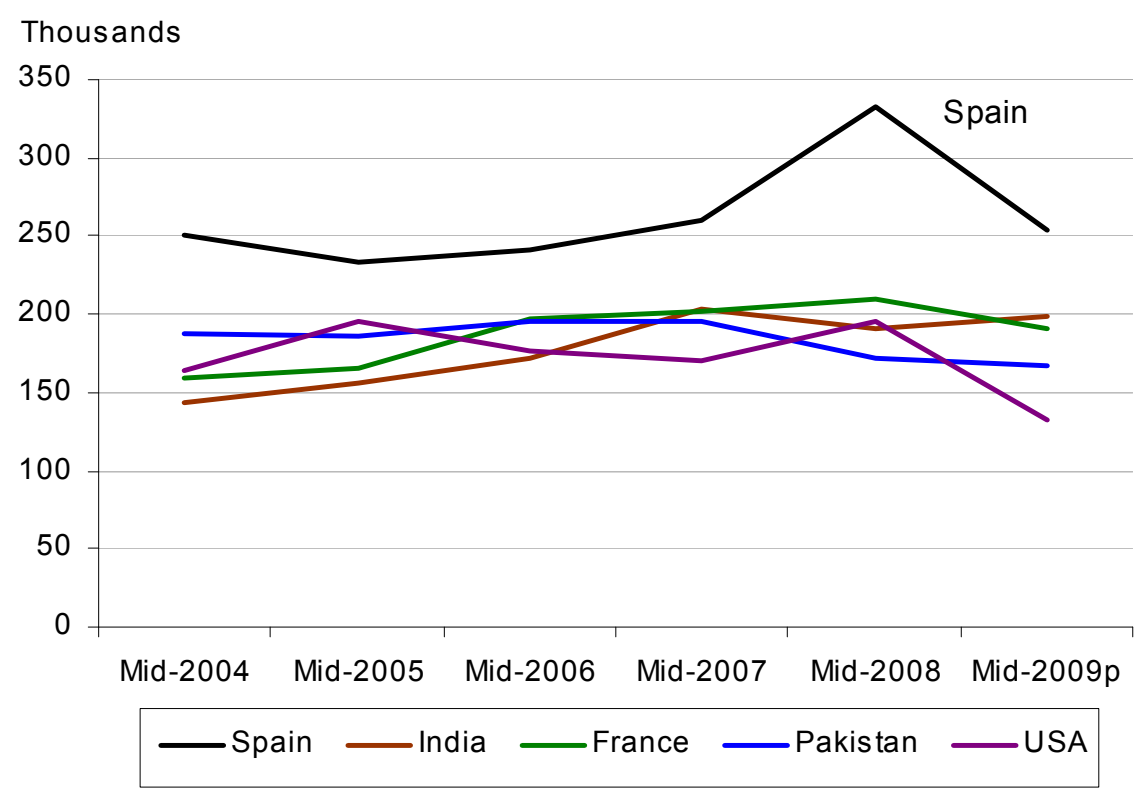

Source: International Passenger Survey, Office for National Statistics Note: $p$ provisional

Figure 11 shows short-term international migration outflows from England and Wales by nationality. The nationality breakdown of the short-term migration outflows is completely different 
from that of the inflows. Outflows of UK nationals dominated total short-term migration outflows in all years.

Figure 12 shows the most popular countries visited by England and Wales residents for all reasons for visit for a period of between 1 and 12 months. Spain was the most popular destination from mid-2004 to mid-2009. However, between mid-2008 and mid-2009 there was a 24 per cent decrease in the number of short-term migrants going to Spain.

\section{Local Authority Level Estimates of Short-term Migration}

So far this article has concentrated on England and Wales level estimates of short-term migration. ONS has also conducted research into producing LA level estimates of short-term immigration. While IPS data can be used directly to estimate for England and Wales, direct IPS estimates are not sufficiently robust at local area level.

Therefore an alternative approach was devised to produce LA level estimate of in-flows made for between one and 12 months. This method is summarised in Figure 13. In this method the IPS short-term migration worker estimate at England and Wales level was distributed to LA level using the number of National Insurance Number (NINo) allocations to overseas nationals in each LA.

\section{Figure 13 Summary flow diagram of local authority level short-term migration estimation methodology}

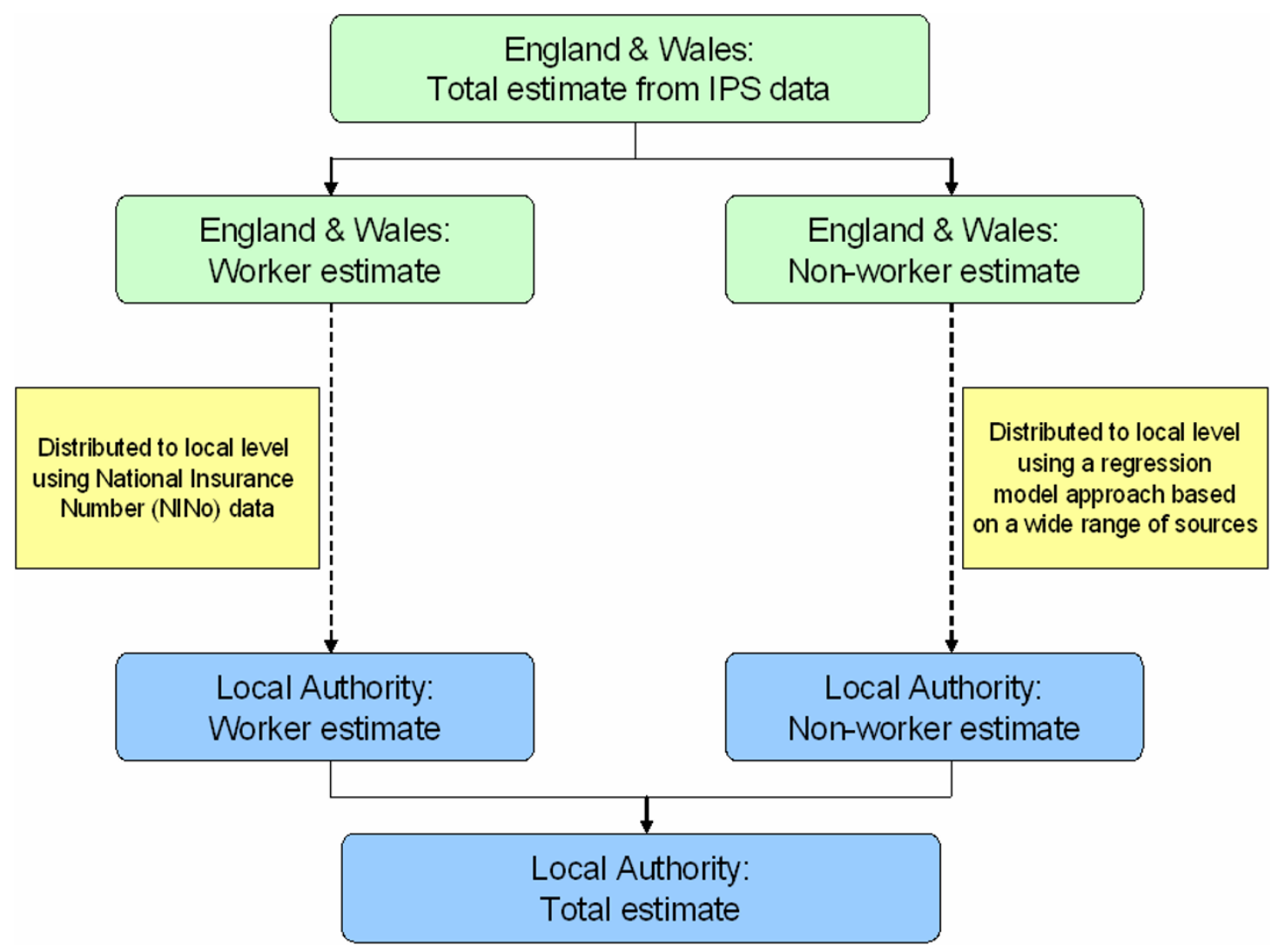

This was the most suitable source to use for distributing short-term migrant workers as most migrants intending to work legally in the UK require a NINo. 
The IPS based England and Wales non-worker short-term migration estimate was distributed to LA level using a regression model. In the model, IPS data was modelled as the dependent variable, and aggregate data at LA level from a number of different sources was entered into the model for potential selection. Examples of these different sources included new registrations with a GP by patients from outside England and Wales (flag 4 data); short-term foreign students from Higher Education Statistics Agency (HESA) data; and data from the 2001 Census on immigrants who moved to England and Wales in the 12 months prior to census but who had been born outside the UK. Using this method an initial set of LA short-term migrant worker and non-worker estimates were produced for the year to mid-2007. Table 1 shows the 10 areas with the largest short-term migration estimates in the year to mid-2007. The distribution of short-term migrants is particularly concentrated in London boroughs and other major urban areas; of these, seven are London boroughs with Westminster having the largest estimate.

\section{Table $1 \quad$ Local Authorities with ten largest short-term migration estimates, mid-2007}

\begin{tabular}{|l|r|}
\hline \multicolumn{1}{|c|}{ Local Authority } & Total short-term migrant estimate \\
\hline Westminster & 62,800 \\
\hline Manchester & 35,900 \\
\hline Birmingham & 33,000 \\
\hline Ealing & 29,200 \\
\hline Camden & 28,000 \\
\hline Barnet & 23,500 \\
\hline Brent & 21,600 \\
\hline Southwark & 21,300 \\
\hline Oxford & 19,500 \\
\hline Wandsworth & 18,800 \\
\hline
\end{tabular}

Figure 14 shows the distribution of short-term migrants across England and Wales in the year to mid-2007. It shows clearly the concentration in London and other cities, particularly those with student populations such as Oxford, Cambridge, Brighton \& Hove and Manchester. The map also highlights concentrations of short-term migrants in the West Midlands and in some agricultural areas of Eastern England such as Boston and Peterborough.

These initial estimates were published in a research report alongside a detailed explanation of the methodology and validation work that had been carried out. A key aim of the report was to invite feedback from users ${ }^{11}$.

A total of 14 LAs and local government organisations provided feedback on the report. The majority of respondents considered the production of LA short-term migration estimates as a significant addition to ONS's migration outputs. They were seen as being important because robust LA level estimates can potentially be used in resource allocation. In addition, LAs require them to help explain the gap that is seen in some LAs between the ONS population estimates, which do not include short-term migrants, and some administrative data sources that include short-term migrants. 
Figure 14 Mid-2007 Local Authority short-term migration estimates as a percentage of the mid-2007 population, England and Wales

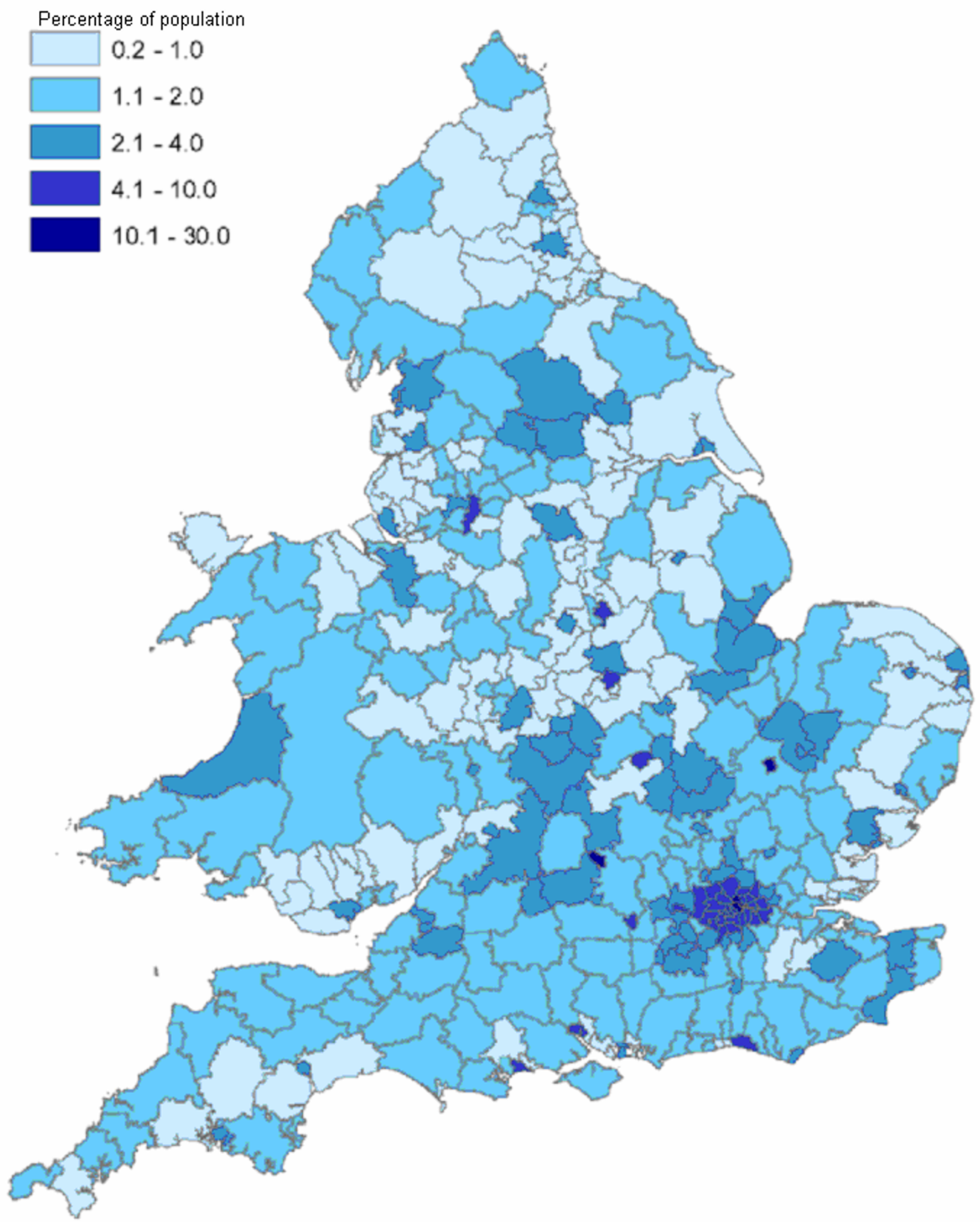

Source: Office for National Statistics 
As a result of the need expressed by LAs for robust LA level short-term migration estimates, ONS is continuing to investigate the possibility of producing LA level estimates of short-term migration. Since the production of the mid-2007 LA short-term migration estimates, ONS has gained access to record level data from several administrative data sources such as the Lifetime Labour-marker Database (L2) and Migrant Workers Scan. The possibility of using these data to develop an improved methodology to distribute national short-term migration totals down to LA level is currently being investigated.

Indicative short-term migration immigration estimates by LA will be made available as soon as the methodology has been fully developed, quality assured, and proven to be robust. This is likely to occur in late 2011 or early 2012. There are currently no plans to produce LA level estimates of short-term emigration.

\section{Conclusion}

This article has provided an update on the progress ONS has made on the development of shortterm international migration statistics. In response to user needs, ONS publish England and Wales level flow and stock estimates for migrants staying for both 1 to 12 months and 3 to 12 months for employment, study, and other reasons (for example, holidays, visiting friends or family, business trips, accompanying and joining friends and family). These have been developed to improve the relevance of migration statistics. This is an appropriate time to highlight this work because in January 2011 the England and Wales level short-term migration statistics were assessed by the UK Statistics Authority against the National Statistics Code of Practice and were granted National Statistic status.

Statistics on short-term international migrants who migrate for 1 to 12 months into and out of England and Wales for work, study and other purposes are presented in this article. The article includes previously unpublished short-term migration statistics. Therefore, this article complements the existing ONS short-term migration publications and helps to give a more complete picture of the size and characteristics of short-term international migration for England and Wales.

The next stage of the development of short-term migration estimates is to build upon existing ONS research and produce robust estimates of short-term migration at LA level. ONS is aiming to make indicative short-term migration estimates by LA available later in 2011 or early 2012. 


\section{Key Findings}

- Short-term migrant workers staying for between 1 to 12 months accounted for a significant part of England and Wales migrant workforce from mid-2004 to mid-2009.

- Poland was the most common country of previous residence for short-term immigrants into England and Wales from mid-2005 to mid-2009.

- Spain was the most common country visited for short-term emigrants from England and Wales for the period mid-2004 to mid-2009.

- Short-term migrant workers are characterised by longer durations of stay compared with students or 'other' migrants. This applies to both inflows and outflows.

- ONS produce short-term migration statistics to meet both the UN definition of a short-term migrant ( 3 to 12 months for work and study) and a broader definition required by users ( 1 to 12 months for all reasons for visit).

- The England and Wales short-term migration estimates were initially published as experimental statistics. These were assessed by the UK Statistics Authority against the strict requirements of the Code of Practice for Official Statistics and were granted National Statistics status in February 2011.

- The European Union enlargement in May 2004 resulted in an increased inflow of short-term migrant workers into England and Wales from Eastern and Central European Accession countries (A8).

- Inflows of short-term migrant workers from A8 countries peaked in mid-2006 and have declined in subsequent years.

\section{References}

1 Office for National Statistics (2006), Report of the Inter-departmental Task Force on Migration Statistics. Available from:

http://www.statistics.gov.uk/about/data/methodology/specific/population/future/imps/updates/ downloads/TaskForceReport151206.pdf

2 Sharfman A, and Smith J (2007), 'The feasibility of making short-term migration estimates', Population Trends, Spring 2007, v 127, p 21-29.

3 United Nations (1998), Recommendations on Statistics of International Migration Revision 1. Available at: http://unstats.un.org/unsd/publication/SeriesM/SeriesM 58rev1E.pdf

4 UK Statistics Authority (2011), Statistics on Short-term Migration for England and Wales Assessment of Compliance with the Code of Practice for Official Statistics. Available at: http://www.statisticsauthority.gov.uk/assessment/assessment/assessmentreports/assessment-report-87---short-term-migration-for-england-and-wales.pdf 
$5 \quad$ Office for National Statistics (2011), Overseas Travel and Tourism - Quarter 32010. Available at: www.statistics.gov.uk/downloads/theme transport/quarterlyQ32011.pdf

6 Office for National Statistics (2007), Summary of Feedback received on the Short-term Migration Feasibility Report. Available at:

www.statistics.gov.uk/about/data/methodology/specific/population/future/imps/updates/downl oads/STM feedback.pdf

7 Office for National Statistics (2011), Mid-2009 Short-term Migration Estimates for England and Wales. Available at: www.statistics.gov.uk/pdfdir/stmig0211.pdf

8 More information on the International Passenger Survey is published on the ONS website and is available at: www.statistics.gov.uk/ssd/surveys/international passenger survey.asp

9 Office for National Statistics (2009), Methodology to produce Short-term Migration estimates for England and Wales, 2004-ongoing. Available at:

www.statistics.gov.uk/downloads/theme population/stmmethodology.pdf

10 Office for National Statistics (2011), Long-term International Migration Tables: 1991 - latest. Available at: www.statistics.gov.uk/statbase/Product.asp?vlnk=15053

11 Office for National Statistics (2009), Research Report on Local Authority level Short-term Migration Estimates. Available at: www.ons.gov.uk/about-statistics/methodology-andquality/imps/updates-reports/historical-updates-reports/updates-reports-09/research-reporton-local-authority-level-short-term-migration-estimates---october-2009.pdf 